\title{
Interaction Design on Model of Adult Education and Network Remote Education
}

\author{
Wu Mingxin ${ }^{1, a}$ Chu Ewei ${ }^{2, b}$ \\ ${ }^{1}$ College of continuing education, Beihang University,Beijing,100191,China \\ ${ }^{2}$ Great Wall Computer Software\&Systems Inc,Beijing,100190,China \\ awmx@buaa.edu.cn, bchuwei@gwssi.com.cn
}

Keywords: adult education, network remote, model, interaction

\begin{abstract}
: based on condition of double-model: adult education and network remote education this paper makes construction on vocational education model for adults, it represents education model by international idea according to combination of network remote model and adult education model, and makes evaluation on relevant techniques of this paper by evaluation and control of adult network remote education, which has obtained strategy discussion on mutual integration of remote education.
\end{abstract}

\section{Introduction}

At present, the adult education in ordinary university is mainly the traditional correspondence education. With acceleration in peace of learning, life and work as well as manner updating ${ }^{[1,2,3]}$, this kind of correspondence education is difficult to accommodate to requirements of times development, it must keep up with the times, update teaching model, apply modern education technology to teaching and increase teaching level. Therefore, active exploration on new model and new idea of Chinese adult education reform and development, profound analysis and research on integration and development of traditional adult education and modern remote education have importance meanings ${ }^{[4,5]}$ to accelerate socialist market economy development, meet development requirement of human resources and construct adult education system conforms to times trend.

This paper adopts methods combined with empirical research and normative research, quantitative research and qualitative analysis to analyze innovation and rationality of education +skill education model that aims at meeting learning requirements of in-service adults and requirements of social economic development on talents implemented by university adult education in transition period, so that it further elaborates the realistic meanings of horizontal communication of university adult education and vocational education, it makes preliminary discussion on horizontal communication of common education and vocational education as well as the problems urgently needs resolution in education model and practice.

Modern remote education model

Change modern education and teaching ideas, update and establish advanced adult education idea. We should construct deep integration of modern remote education and traditional and adult further education, systematic education idea and system. Construct communication and integration model of 2 kinds of education forms in admission manner. Discuss integration strategy of modern remote education and traditional further education in teaching manner and teaching process; gradually promote systematic research on further education of higher education and multi-media teaching materials. Deepen student's status management of higher further education, digitization and integration research of assessment and evaluation.

We should establish modern adult education idea, make clear vague understanding in idea universally existed in field of higher further education, such as enrollment standard, teaching material, teaching, assessment, quality, education grade etc in modern remote education and traditional adult further education. We should resolve problems such as different enrollment channels and disorder competition, separate independence in teaching material and supplemental materials, self-contained, repeated construction, difficulty in complementary advantages, wistful action and non communication etc. We should also resolve nonstandard student's status management, non-uniform 
assessment standard and multiple of evaluation manners, mutual contradiction in academic year system and credit system, un-free certification channel etc.

This paper constructs education idea system of 2 kinds of ways of running schools in deep integration. It persists in integration theory and objects replacement idea, concerns effect of network on education and revolutionary reform of this kind of effect on future education and teaching model. It advocates fully using modern information and technology means to develop adult education, coordinated development and integrate each kind of social education resources, accelerate construction and sharing of high-quality education resources, at the same time, it displays advantages of original education manner, holds principles of strengthening classified instruction and encouraging diversified development, as well as realize mutual reference and mutual integration of multiple kinds. It deeply discusses and constructs detailed models of 2 kinds of education models in enrollment, teaching method, management as well as assessment and evaluation integration on the basis of problems exists in adult education of higher university at present. As it is indicated by diagram 1, which indicates graduates of college level in applied technology cultivated by this model. They not only have certain scholar base but also have stronger vocational ability. Their employment and competition abilities, self-development and social adaptation abilities have got enhancement. So this major not only has better social demand, which presents better development trend. 学

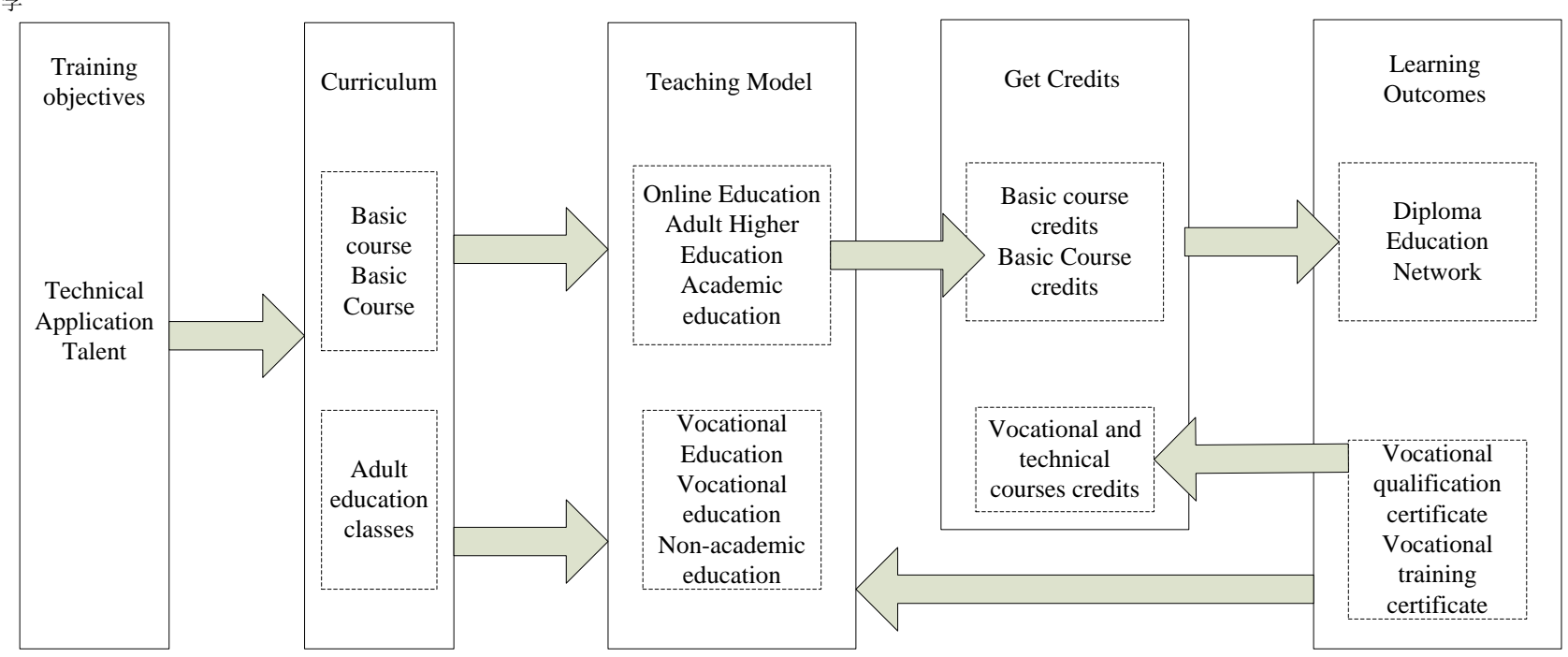

Diagram 1 Remote network education model of adults

According to the analysis process from downside to upside, the general network education resources pool of middle school should be composed by the following parts, its structure is generally composed of public resources base pool of campus network, personal resource pool of teachers and students, resources management platform, personalized operation of users, resources application and access interface (it is classified as teacher and student module), which is indicated by diagram 2. Of which, the resources in pubic resources pool is uniformly management by system, any users have no rights in management and operation on resources in this part. According to difference in data content and access particle in public resources pool, it is generally divided into base resources, integrated unit and teaching courseware, of which base resources generally includes the basic unit included by education resources, such as text resources, multi-media resources pool, website pool, usual problems pool, noun and tern pool as well as basic symbol and pattern pool of each subject. The compound resources composed of basic units is stored in integrated unit, such as course and examination questions pool, micro-teaching unit pool, case pool, reference data pool and sharing software pool etc. As for courseware resources, it includes different courses, electronic teaching plans, electronic lecture, lesson video, electronic books and disc courseware etc distributed by different teachers. In order to make it convenient for teachers and users to share education resources mastered by them according to lecture demand, system structure includes personal resources pool, which means every 
teacher can manage his own education resources by way of file. It allows personal resources to turn into public resources through review or authorization by system administrator.

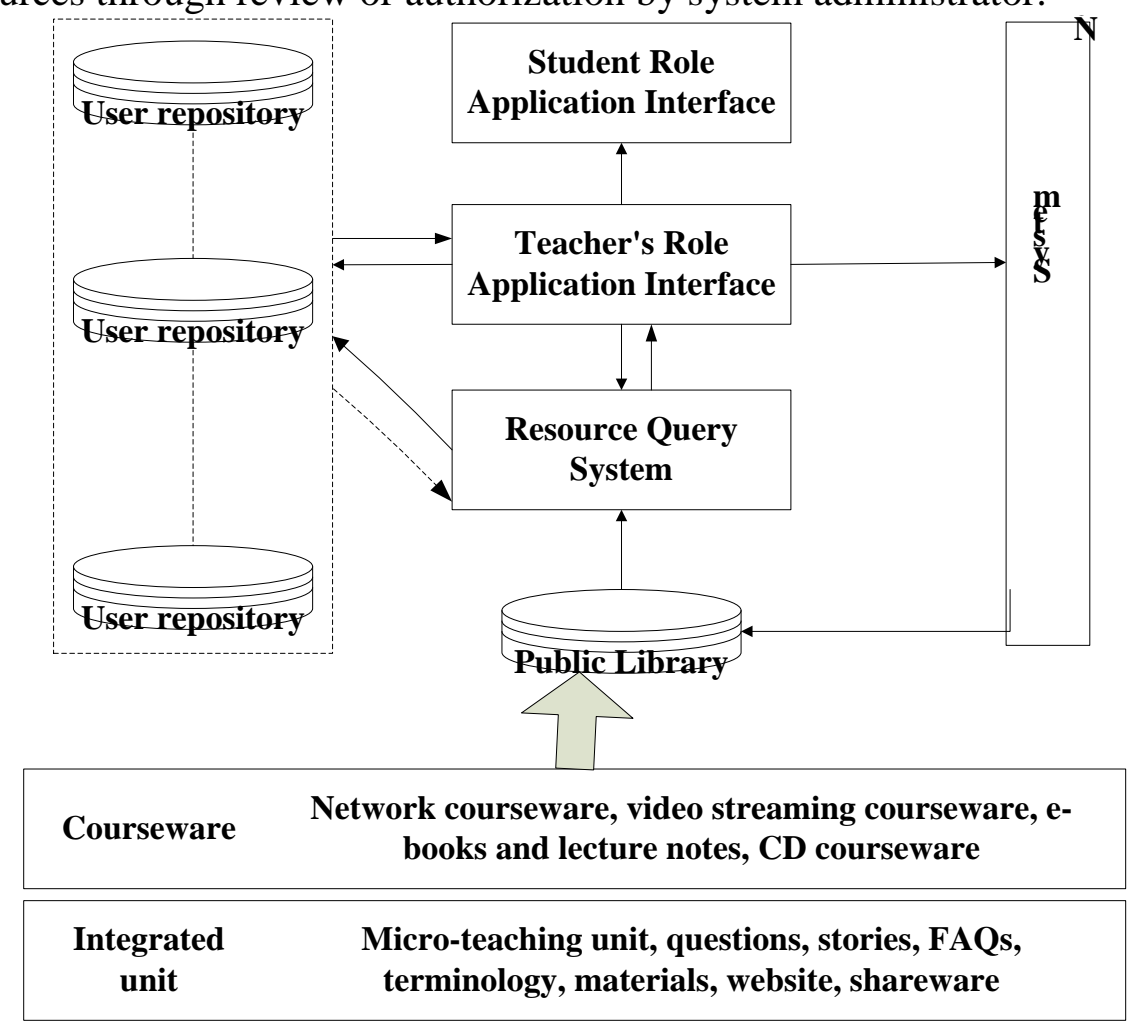

Diagram 2 Adult remote network education resources model

\section{Evaluation and control of adult network remote education model}

Suppose professional guidance, partner cooperation and teacher-student interaction are respectively indicated by $\mathrm{a}_{\mathrm{ij}}, \mathrm{b}_{\mathrm{ij}}, \mathrm{Z}_{\mathrm{ij}}$, in order to make multi-node control on English teaching, it considers that neutral coupling complicated and dynamic network system with $\mathrm{N}$ the same nods:

$$
\bar{x}_{i}(t)=f\left(x_{i}(t)\right)+\varphi(t) \sum_{N} a_{i j} \Gamma_{x_{j}}(t)+\alpha \sum_{N} b_{i j} \overline{x_{j}}(t)+\beta \sum_{N} c_{i j} \bar{x}_{i}(t)
$$

In the formula, $x i(t)=\left[x_{i_{1}}(t), x_{i 2}(t), \ldots, x_{i n}(t)\right] \mathrm{T} \quad$ ERRdicates state vector of the $\mathrm{i}$ node, $f: \mathrm{R}^{n} \times \mathrm{R} \rightarrow \mathrm{R}^{n}$ is smooth and non-linear function, $\alpha$ is the known changeless non-negative parameter, $\phi(t)$ indicates unknown changeable coupling strength. $\Gamma=\operatorname{diag}(\gamma 1, \ldots, \gamma n)$ is the internal coupling matrix.。 $A=\left(a_{i j}\right)^{N^{\times}} N \in \mathrm{R}^{N^{\times}} N$ and $B=\left(b_{i j}\right)^{N^{\times}} N \in \mathrm{R}^{N^{\times}}, \mathrm{C}=\left(c_{i j}\right)^{N^{\times}} \in \mathrm{R}^{N^{\times}}$are all external coupling matrix, indicating topology structure of complicated network, if $a_{i j}=10\left(b_{i j}=0\right)$, then indicates node $j$ has effect on dynamics behavior of node $i$,there one side from node $j$ to node $i$, its weight is $a_{i j}\left(b_{\text {i回罒, }}, \mathrm{C}_{\mathrm{ij}}\right)$. Diagonal element matrix $A, B, \mathrm{C}$ meet consumption condition: $a_{i i}=-N \sum a_{i j}=1, j=/ i a_{i j}<0$, $b_{i i}=-N \sum \mathrm{b}_{\mathrm{ij}}=1, j=i b_{i j}<0, \mathrm{c}_{i i}=-N \sum \mathrm{c}_{\mathrm{ij}}=1, j=i \mathrm{c}_{i j}<0, i=1,2, \ldots, N$ 。

Coupling matrix of network $\Gamma, A$ respectively meets the following: $\|\Gamma\|=\gamma,\left|a_{i j}\right| \leqslant a, \forall i, j=1$, $2, \ldots, N$ 。

In order to realize synchronization of each node in dynamic network, it uses self-adaptation strategy to make control on network $u i(t)$, then then network system under control is described as follows:

$$
\bar{x}_{i}(t)=f\left(x_{i}(t)\right)+\varphi(t) \sum_{N} a_{i j} \Gamma_{x_{j}}(t)+\alpha \sum_{N} b_{i j} \overline{x_{j}}(t)+\beta \sum_{N} c_{i j} \bar{x}_{i}(t)+u_{i}(t)
$$

Of which, $u_{i}(t)=\left[u_{i 1}(t), u_{i 2}(t), \ldots, u_{i n}(t)\right] \mathrm{T} \quad$ (qif $\left.1,2, \ldots, N\right)$ is self-adaptation controller waiting for design.

Multi-interaction is the effective channel to cultivate reconsideration ability, interaction manner and content are indicated and penetrated into self-reconsideration of teachers, making teachers 
internalize cognition and get methods in this process, which can really indicate cultivation and enhancement of their reconsideration ability. Cultivation of multi-element interaction and reconsideration ability makes up the lasting and good circulation on professional development of teachers. Enhancement can make them better survey their teaching behaviors and learning effect of students. It pertinently uses feed back of students on teachers to improve and adjust learning, enhance interaction quality between teachers and students.

Intelligent individual can play different roles, learning effect is also different, so it can not keep the same reward under this condition, as for the ordinary cooperative multi-intelligent agent reinforcement learning, it regards the extracted individual reward as one kind of reliability allocation way, strategy and integrated awards of other intelligent agents are unknown, which has become to be barrier for EIR acquisition.

$$
r\left(s, a^{i}\right)=\sum_{a^{1} \in A^{1}} \ldots \sum_{a^{t-1} \in A^{t-1}} \sum_{a^{t+1} \in A^{t+1}} \ldots \sum_{a^{N} \in A^{N}} \prod_{j=1, j \neq i}^{N} \pi_{*}^{j}\left(a^{j} \mid s\right) r(s, a)
$$

Learning intelligent agents make observation on behaviors and actions of other intelligent agents under the integrated state, and it is recorded as $\pi\left(a^{j} \mid s\right)$, it is the prediction strategy of learning intelligent agents on partner intelligent agent $\mathrm{j}$, the probability of intelligent agent $\mathrm{j}$ implements action $a^{j}$ under the integrated state, there is obviously the following

In order to reduce calculation complication and storage of known space, we adopt Robins-Monro method [7] to predict strategy of other intelligent agents. At time t, when intelligent agent observes implementation action $a_{t}^{j}\left(a_{t}^{j} \in A^{j}, j \neq i\right)$ of intelligent $\mathrm{j}$, we adopt the following way to make update on its strategy.

$$
\bar{\pi}_{t+1}^{j}\left(a^{j} \mid s\right)=\left(1-u_{t}^{j}\right) \bar{\pi}_{t+1}^{j}\left(a^{j} \mid s\right)+ \begin{cases}u_{t}^{j} & \text { if } \quad a^{j}=a_{t}^{j} \\ 0 & \text { otherwise }\end{cases}
$$

Of which, $\bar{\pi}_{t+1}^{j}\left(a^{j} \mid s\right)$ indicates the estimated strategy renewal of intelligent agent $\mathrm{j}$ implements action at time t,,$u_{t}^{j}(0<\mathrm{u}<1)$ indicates the updated learning ratio, then this order $u_{t}^{j}$ meets the following conditions

$$
\sum_{t=0}^{\infty} u_{t}^{j}=\propto, \sum_{t=0}^{\infty}\left(u_{t}^{j}\right)^{2}<\propto
$$

It makes when $\mathrm{t} \rightarrow \propto$, there is $\bar{\pi}_{t+1}^{j}\left(a^{j} \mid s\right) \rightarrow \pi_{t+1}^{j}\left(a^{j} \mid s\right)$ 。

\section{Demonstration and evaluation on adult education and internet remote model}

It uses SPSS19.0 to make statistics and analysis, because the variable of this investigation is discrete variable, so when it detects different age stages, that is 20,30 and 40 , it applies non parametric independence and multi-sample detection on effect of evaluating data difference significance of cooperative learning on self-English level.

As it is indicated by diagram 1, according to SPSS result, the test class that is the preliminary test result of students in administrative management are all 65.44(full credit is 100 marks). Control class, the preliminary test result of business administration are all 66.72, Sig(2-tailed) $=0.305>0.05$, the data indicates that 2 groups have no obvious difference in English learning ability and level. 
Table 1 Independent sample test

\begin{tabular}{|c|c|c|c|c|c|c|c|c|c|}
\hline & \multicolumn{2}{|c|}{$\begin{array}{l}\text { Levene test of } \\
\text { variance } \\
\text { equation }\end{array}$} & \multicolumn{7}{|c|}{ T test of average equation } \\
\hline & \multirow[t]{2}{*}{$\mathrm{F}$} & \multirow[t]{2}{*}{ Sig. } & \multirow[t]{2}{*}{$\mathrm{T}$} & \multirow[t]{2}{*}{$\mathrm{df}$} & \multirow[t]{2}{*}{$\begin{array}{l}\text { Sig } \\
\text { (double } \\
\text { sides) }\end{array}$} & \multirow[t]{2}{*}{$\begin{array}{c}\text { Mean } \\
\text { difference }\end{array}$} & \multirow{2}{*}{$\begin{array}{c}\text { Error } \\
\text { value of } \\
\text { standard } \\
\text { deviation }\end{array}$} & \multicolumn{2}{|c|}{$\begin{array}{l}95 \% \text { confidence } \\
\text { interval of } \\
\text { difference }\end{array}$} \\
\hline & & & & & & & & $\begin{array}{c}\text { Lower } \\
\text { limit }\end{array}$ & $\begin{array}{c}\text { Upper } \\
\text { limit }\end{array}$ \\
\hline $\begin{array}{l}\text { Assumed } \\
\text { variance }\end{array}$ & 1.060 & .305 & .846 & 167 & .399 & .878 & 1.038 & -2.928 & 1.172 \\
\hline
\end{tabular}

The left picture in diagram 3 indicates the process of EIR approximation corresponds to state and action $<14,8,0.4, \pi / 2>$. In the early time of EIR approximation, because function EDR of state $<14,8>$ has not completely converged, learning intelligence has larger probability on search, so EIR approximation has bigger fluctuation. With the increase of iteration times, EIR has converged approximately to value of constant 10 . This means if the partner adopts self optimal strategy, then learning intelligence is in state of $\langle 14,8\rangle$, it can reach target state after adopting corresponding action, the state and action value function 4,8,0.4, $\pi / 2$ ) has converged approximately to position of 10 under the optimal response algorithm learning, which indicates the effectiveness of EIR approximation strategy. According to the above analysis, under the MARL-TT algorithm, the intelligent agent indicates better reliability allocation; replaced learning of intelligent agent has obtained the optimal response strategy of other intelligent agents through replacement and trace structure. In addition, from the perspective of overall state, it can be regarded as one kind of learning that is happening at the same time of on looking.
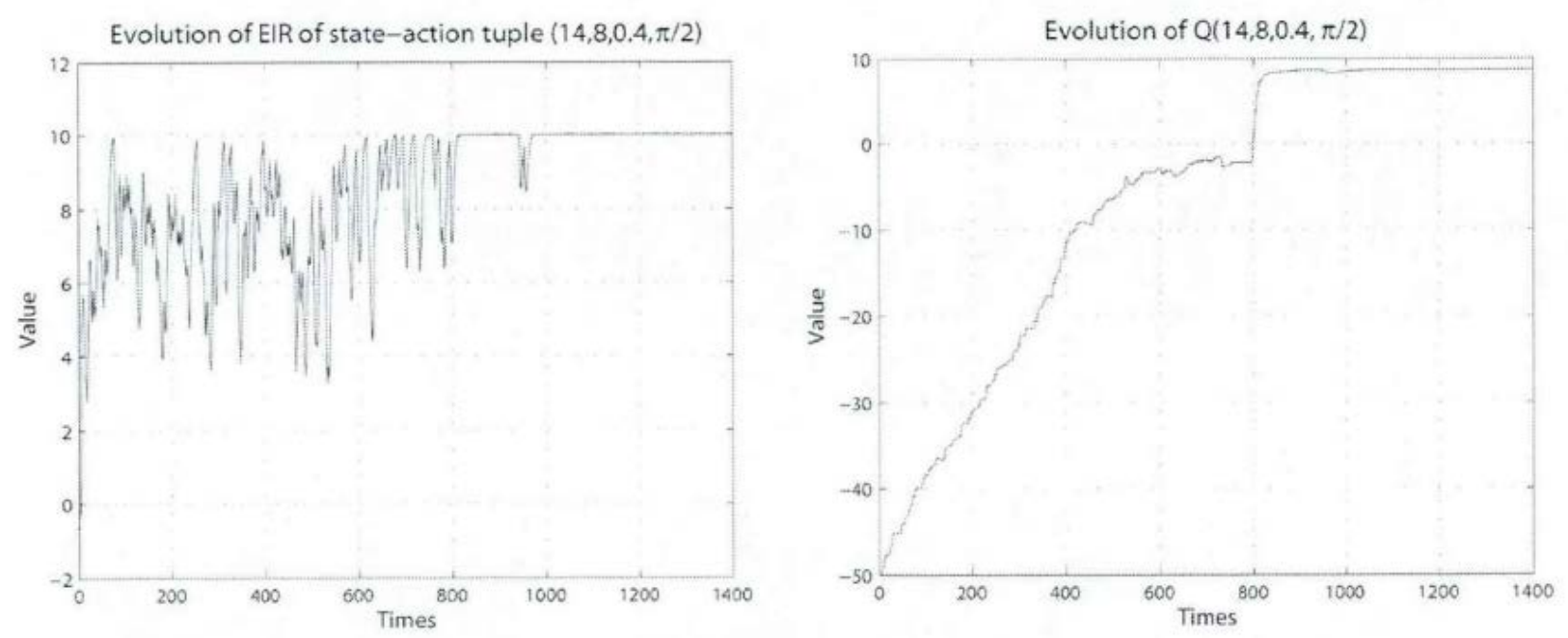

Diagram 3Make sampling and tracking on EIR and Q value evolution correspond to independent action of certain integrated state

\section{Further integration strategy of modern remote education and traditional adult education}

\section{Change education idea and eliminate internal friction of competition}

Make adjustment and special training for staff, make powerful propaganda and education for learners, and make preparations for teaching manner and evaluation manner of adopting integration. Regard higher education of adult as one special education activity different from traditional school education in idea, aiming at establishing prefect adult higher education system, cultivating employee in adult education through special training and forming systematic adult education theory. Change knowledge idea, actually increase life skills of learners, enhance work ability, and establish one kind of new and extensive knowledge idea. Change curriculum idea, the set curriculum needs to combine with social demand and self demand of learners, combine with systematic teaching content with 
knowledge practicality, establish systematic knowledge structure through curriculum learning, and be good at using the learned knowledge to solve practical problems, really increase their work skills, acquire subject knowledge and enhance learning ability through learning.

\section{Make reform in teaching model and realize most optimum distribution of resources}

Greatly accelerate reform in teaching model is the power of guaranteeing integration and development of modern remote education and adult further education. The learners of remote education college, network education and correspondence education after integration all can make internet education on demand and practical teacher-student interaction and integrated education according to their demands, which can not only solve work and learning contradiction of some learners, but also can meet willing of some learners requirements of realizing interaction between teachers and students. Teachers and upload courseware, teaching materials, distribute information, correct work of students, solve difficult problems after registration and login. As for exploration on teaching model, they can make integration on network teaching, video teaching, broadcast and TV etc according to self characteristics of learners and requirement of teaching target, absorb advantages of traditional teaching model and integrate education resources, making teaching models of different forms and patterns mutually integrated with each other, strengthen education and reform strength, form integrative teaching model and system, establish new education model of modern remote education and adult education that accommodate to national conditions of China, accelerate autonomic learning of learners and actually realize effective learning of majoring in learners.

Comprehensively apply teaching resources and strengthen investment in infrastructure

Establish teaching resources of material class including questions pool, media resources, test paper, courseware, teaching plan and teaching resources, make development on evaluation of internet curriculum construction and resources construction, education and resources management system formed by every kind of education resources according to systematic characteristics of subject knowledge and difference of network teaching. We should confirm organization and construction procedure, teaching resources needs to establish organization such as instruction commission, functional department and evaluation commission, the design should include teachers, learners, teaching resources and establishment procedure of education evaluation.

\section{Change management model of education and increase management efficiency}

Correspondence education and network education need to establish a whole set of education management rules and prefect mechanism, develop remote education by relying on current correspondence point, use current infrastructure and human resources at the same time improve internet infrastructure of correspondence point, meanwhile, learn lesson from mature management system and supervision mechanism of correspondence education, completely display the radiation effect of every correspondence station in the process of developing teaching, make well in conventional teaching and guidance.

\section{Strengthen establishment in teaching staff}

In the implementation process, we need to establish one technology support team with good skills; they can provide each kind of technology support for vast teachers and students at any time. They can make standardization and reform on teaching and management team by integration change, make uniform assessment for current administrators of educational administration, select the students according to the marks they get, as for correspondence point needs further expansion, school can recruit one batch of talents with higher education, strong ability as well as management qualification and computer base through uniform recruitment or autonomous recruitment in correspondence point. Make uniform management, uniform dispatch, and assessment of fixed period for all the teaching administrators. Every university should make corresponding budget, which is used for special training, investigation and learning of teaching administrators.

\section{Establish quality evaluation system suitable for new adult education}

Take into consideration of school work, learning, practice, answer questions on internet and make effective analysis, realize complete evaluation. On establishing prefect network evaluation system, adult education and teaching integration after merging should not only make identification, judgment for simple judgment questions and choice questions, but also should strengthen system establishment 
on key words identification for essay questions, so that it can make effective investigation on comprehensive ability of learners. Except for this, we should also establish system of data and subject analysis on school work, test and exam of learners, extract questions of deeper level from plenty of information, provide guidance for teachers to adjust teaching. We should establish perfect mechanism for integration based on teaching resources, course mergence, organization and management on exam as well as compilation of test paper and judgment standard.

\section{Summary}

Modern remote education accelerates separation between teachers and learners, it applies multi-media teaching means of modern network technology, which breaks through limitations in traditional teaching time and space, enlarges teaching scale, it also provides possibility for further enhance teaching quality, traditional adult education has mature development mechanism and long-term mechanism, it establishes relatively prefect infrastructure and evaluation system, it provides support on further working and high-efficiency life of educators, it is also the effective ways for correspondence education enhance scale and quality. Application of internet and information technology is the necessary way for development of correspondence education, future of adult education will be much better.

\section{References}

[1] Ye Zhonghai.Adult Higher Education. Tongji University Press,2011， p 12-21.

[2] Tang Li. Integration of University Modern Remote Education and Full-time Undergraduate Education in Education Informatization. China Adult Education, 2013, Vol 1 20-25

[3] Li Xiaoyun,Yang Shengshun.Research on State and Development Strategy of Further Eduication In Qinghai Province.Adult Education,2013, p 29-30.

[4] Mi Mei Internet Curriculum Establishment and Evaluation Research on Adult Education.Shanxi Normal University, 2007, p18-20.

[5] Shi Zhijin, Li Yanping. Consideration on Concept of Adult Education. Adult Education College Journal of Hebei University, 2010,Vol 6,p112-114.

[6] Bao Huaying. Consideration on Key Problems of Development of Furher Education.China Remote Education 2012, Vol2, p 139-143.

[7] Yang Baoshan. Research on School Work Evaluation under Support of Internet Technology. China Remote Education, 2011, Vol 9. p228-233. .

[8] Wang Li, Zhang Jingsheng etc. New Curriculum Idea and Internet Curriculum Design. China Remote Education, 2011, p20-21.

[9] Zhang Youfang. Innovation in Students Management Model of Remote Open Education. China Remote Education,2011,vol 12, p49-53. 